
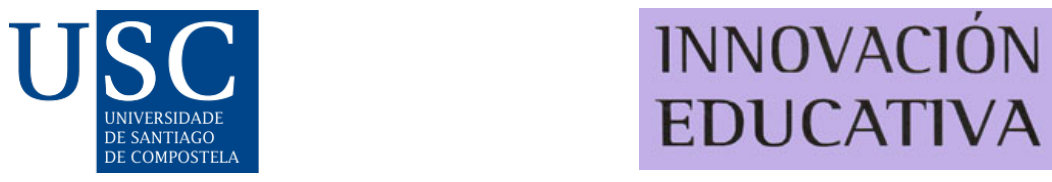

Innovación Educativa, (31), 2021. ISSN-e: 2340-0056

https://doi.org/10.15304/ie.31.7631

Artigos

\title{
ESTUDIO DE PERTINENCIA PARA EL PROGRAMA DE NEGOCIOS INTERNACIONALES EN MODALIDAD EN LÍNEA DE LA UNIVERSIDAD DE OTAVALO
}

\section{STUDY OF RELEVANCE OF THE PROGRAM IN INTERNATIONAL BUSINESS, ON LINE MODALITY, IN OTAVALO UNIVERSITY}

\author{
Santiago Núñez Naranjo ${ }^{1, a}$ (D), Soledad De la Torre Altamirano ${ }^{2, b}$ (iD \\ ${ }^{1}$ Universidad de Otavalo, Ecuador \\ ${ }^{2}$ Universidad de Otavalo, Ecuador \\ a snunez@uotavalo.edu.ec b mdelatorre@uotavalo.edu.ec
}

Recibido: 13/04/2021; Aceptado: 01/09/2021

\section{Resumen}

El presente documento muestra los resultados del estudio de pertinencia para la carrera de negocios internacionales en modalidad en línea de la Universidad de Otavalo-Ecuador en 2020. El trabajo tuvo como objetivo determinar cuán pertinente es la propuesta en el contexto actual para la sociedad ecuatoriana. Para ello, se desarrolló una metodología basada en 4 componentes clave: necesidades y problemáticas de los negocios internacionales, tendencias de desarrollo en relación con la evolución de la problemática identificada, articulación de la propuesta con la problemática identificada, los objetivos, metas y políticas de los cuerpos normativos del país; y el estudio de mercado. Se demuestra que el escenario actual es el propicio para incursionar con programas innovadores en modalidad en línea, que existe una alta demanda de personas que requieren la profesionalización en negocios internacionales y a la vez una baja oferta en modalidad en línea de programas similares.

Palabras clave: pertinencia; negocios internacionales; modalidad en línea; educación superior; calidad.

\begin{abstract}
This document shows the results of the study of relevance carried out at the Ecuador level for the International Business career, in online modality, at Otavalo University in 2020. The objective of this paper was to determine how pertinent this career is for the Ecuadorian society in the current context. The methodology was based on 4 key elements: necessities and problems of international business, development trends in relation to the evolution of the identified problem, articulation of the educational proposal with the identified problem, with the objectives, goals and policies of the normative bodies in Ecuador and the market study for the proposal. It is demonstrated that the current scenario is conducive to venturing into innovative programs in online mode, that there is a high demand for people who require professionalization in international business and, at the same time, a low offer in online mode of similar programs.
\end{abstract}


Keywords: relevance; international business; on line modality; higher education; quality.

\section{INTRODUCCIÓN}

El concepto de pertinencia educativa ha evolucionado vertiginosamente. Este ha ido avanzando desde una visión economicista de la oferta formativa a nivel superior para su tecnificación y aporte a la economía hasta una visión más humanista y complementaria que involucra una estrecha vinculación con la calidad, la equidad, la responsabilidad social (Berhein, 2011), la diversidad, el diálogo intercultural y los contextos en que se desenvuelve. La pertinencia ya relacionada con la calidad y el mejoramiento continuo refiere a mostrar que las universidades responden a la comunidad, a su contexto y a su realidad contextual de forma en que no exista una imposición de criterios ajenos a los sujetos.

Desde inicios del siglo XXI, se consideró a la pertinencia como un concepto inclusivo que involucraba calidad e internacionalización, términos que han delineado la base teórica del estudio. Para lograr y mantener la calidad de la educación superior, son importantes la selección esmerada del personal y su perfeccionamiento constante, la promoción de planes de estudios adecuados, programas que faciliten la movilidad de profesores y estudiantes y el uso de las nuevas tecnologías, sin perder de vista la referencia a lo social y al bien común (UNESCO, 1998).

En Ecuador, la educación superior ha publicado nuevas directrices, lo que ha significado que las Instituciones de Educación Superior (IES) transformen sus procesos educativos, "generando nuevas estrategias, que superen tanto los desafíos locales como las demandas del siglo XXI" (Bonilla, 2019 , p. 15). En este contexto, el estudio de pertinencia desarrollado por la Universidad de Otavalo para la carrera de negocios internacionales en la modalidad en línea no se centra meramente en un análisis de mercado, sino en una investigación más completa, que aborda: las necesidades y problemáticas de los negocios internacionales a nivel internacional y nacional; las tendencias de desarrollo regional y local en relación con la evolución de la problemática identificada con atención al rol que cumple la carrera; la articulación de las problemáticas identificadas con los objetivos, metas y políticas de los cuerpos normativos del país, principalmente con los de planificación oficial del Ecuador; y en un análisis de la oferta así como de la demanda estudiantil y ocupacional, en el que se detalla las funciones, roles de los escenarios laborales en el que actuarán los futuros profesionales (Consejo de Educación Superior, 2019, p. 12). Este estudio pretende responder a la pregunta: ¿cuán pertinente es la carrera de negocios internacionales en modalidad en línea en el territorio ecuatoriano, específicamente en la Sierra Norte? Sus resultados se presentan a lo largo de este documento con el fin de crear un programa curricular ajustado a las necesidades y requerimientos de la sociedad y sus interesados, buscando fortalecer la oferta exportable ecuatoriana no tradicional.

\section{MÉTODOS Y MATERIALES}

Se ha planteado una metodología mixta basada en la recolección de información en 4 componentes clave: necesidades y problemáticas de los negocios internacionales, tendencias de desarrollo en relación con la evolución de la problemática identificada, articulación de la propuesta 
educativa de la Universidad de Otavalo con la problemática identificada, con los objetivos, metas y políticas de los cuerpos normativos relacionados y el análisis de la oferta de carreras similares, así como de la demanda estudiantil y de la demanda ocupacional en Ecuador (el cual se basa en la opinión de los empleadores).

Se lleva a cabo en primera instancia una revisión bibliográfica de fuentes secundarias de instituciones oficiales a nivel internacional y nacional respecto a la conceptualización actualizada del término pertinencia en el sector educativa; destacan la Organización de las Naciones Unidas (ONU), la Organización de las Naciones Unidas para la Educación, la Ciencia y la Cultura, (UNESCO), la Comisión Económica para América Latina y el Caribe (CESPAL), la Secretaría Nacional de Educación Superior, Ciencia, Tecnología e Innovación (SENESCYT), el Consejo de Educación Superior (CES), el Consejo de Aseguramiento de la Calidad de Educación Superior (CACES), Secretaría Técnica Planifica Ecuador y otras relacionadas a la facilitación y fomento de los negocios internacionales como la Organización Mundial del Comercio (OMC), Comisión Económica para América Latina y el Caribe (CEPAL), Instituto de Promoción de Exportaciones e Inversiones (PROECUADOR). Sus estudios se han revisado con el fin de describir el contexto normativo en el que se plantea la propuesta y relacionarlo con el desempeño productivo y las variables de pertinencia de la carrera de negocios internacionales definidas para su respectivo análisis.

Posteriormente, se aplican instrumentos de levantamiento de información (encuestas) que sirvieron como fuentes primarias para el análisis de la oferta académica existente, y de la demanda actual. Este último rubro incluyó una revisión del mercado potencial y de los empleadores para la determinación de los escenarios reales en donde se podrían desempeñar los estudiantes graduados de la carrera de negocios internacionales, modalidad en línea, de la Universidad de Otavalo. En total se han planteado levantar 1839 encuestas en respaldo del estudio, las cuales están divididas en 4 fases: 675 encuestas destinadas a propietarios de negocios en las provincias de Pichincha, Imbabura y Carchi, principales lugares de impacto de la actividad educativa de la universidad objeto de estudio; 584 encuestas a bachilleres de colegios públicos y privados de los mismos sitios; 358 propietarios de empresas de actividades relacionadas con el comercio y los negocios internacionales; y 222 encuestas a personas económicamente activas entre 18 y 44 años que no han podido obtener su título universitario.

\section{ANTECEDENTES}

\subsection{Necesidades y problemáticas de los negocios internacionales}

El nuevo orden económico mundial, las constantes crisis del sistema financiero, y la crisis sanitaria provocada por la pandemia del COVID-19, han desencadenado transformaciones en el desempeño de las economías y en las problemáticas respecto de diversas áreas, de las que no se exceptúa los negocios internacionales. Dichas transformaciones han reconfigurado el contexto global de los negocios en 2020, un año convulsionado y marcado por una caída de la economía mundial que ha venido respaldada por una amenaza de pérdida de legitimidad de las instituciones internacionales que ha contrapuesto políticas comerciales de países desarrollados, emergentes y en desarrollo. Por efectos globales del coronavirus, la caída de las bolsas y la baja en el precio de las materias primas, se sumó la caída del petróleo, el pánico ha contagiado a los mercados (El Universo, 
2020). En dicho escenario, se develan problemáticas a resolver (ver Tabla 1), de las que destaca una reducción del Producto Interno Bruto (PIB) mundial, hasta en un 5.2\% (Banco Mundial, 2020). Sin embargo, para los países en vías de desarrollo, se prevé una afectación mayor al promedio; en América Latina del 9.1\% aproximadamente hasta el final del año (CEPAL, 2020). Este problema genera consecuencias que se las cataloga como necesidades a suplir, las cuales se presentan a continuación:

Tabla 1. Necesidades, problemas y soluciones en el campo de los negocios internacionales a nivel mundial

\begin{tabular}{|c|c|c|}
\hline NECESIDADES & PROBLEMAS & SOLUCIONES \\
\hline $\begin{array}{l}\text { Capacitación y } \\
\text { formación profesional } \\
\text { en el ámbito de los } \\
\text { negocios electrónicos, a } \\
\text { través de un } \\
\text { entendimiento del nuevo } \\
\text { orden mundial, el } \\
\text { contexto de crisis } \\
\text { económica, financiera y } \\
\text { sanitaria. } \\
\text { Alternativas sostenibles } \\
\text { de empleo y de } \\
\text { inserción laborar en un } \\
\text { escenario de caída del } \\
\text { empleo formal y de la } \\
\text { quiebra de empresas. }\end{array}$ & $\begin{array}{l}\text { Acelerada transformación digital } \\
\text { para la generación de negocios } \\
\text { digitales. } \\
\text { Alta oferta de capacitación } \\
\text { empírica de los negocios, no } \\
\text { científica. } \\
\text { Diferenciación en el desarrollo } \\
\text { económico de los países. Se } \\
\text { han incrementado las brechas } \\
\text { económicas entre países. } \\
\text { Escaso empleo por la baja } \\
\text { formación profesional y } \\
\text { académica en el área de los } \\
\text { negocios. } \\
\text { Sobreoferta de bienes, y escasa } \\
\text { transformación de la matriz de } \\
\text { producción de los países en } \\
\text { desarrollo. }\end{array}$ & $\begin{array}{l}\text { Ofrecer una oferta académica de } \\
\text { formación profesional que permita } \\
\text { identificar las características del } \\
\text { nuevo orden mundial y la relación } \\
\text { comercial entre los actores } \\
\text { comerciales a nivel mundial. } \\
\text { Fomentar la investigación y la } \\
\text { innovación empresarial a través de } \\
\text { proyectos académicos que } \\
\text { permitan a la sociedad hacer frente } \\
\text { al empirismo de hacer negocios y } \\
\text { mejorar la integración regional a } \\
\text { través de la interculturalidad y } \\
\text { fomento al comercio. } \\
\text { Impulsar la formación de talento } \\
\text { humano en el área de negocios } \\
\text { internacionales para la } \\
\text { internacionalización. }\end{array}$ \\
\hline
\end{tabular}

Fuente: Elaboración propia.

El crecimiento del empleo en los países de altos ingresos se produjo a costa de reducir el crecimiento de la productividad laboral, ya que los puestos de trabajo se crearon principalmente en el sector de los servicios, en el que el valor añadido medio por trabajador es relativamente bajo. Por el contrario, países de ingresos medios que han sufrido crisis económicas, en los últimos años, mantienen tasas de desempleo elevadas; es poco probable que vuelvan a lograr un fuerte crecimiento del empleo en el futuro próximo, en vista de las perspectivas poco prometedoras principalmente para los países en desarrollo en el contexto de la economía mundial de la que Ecuador forma parte (Organización Internacional del Trabajo, 2020). La especialización productiva primario-exportadora y secundario-importadora que drena los recursos y vuelve vulnerable al Ecuador frente el mercado exterior, configura el contexto internacional de persistente heterogeneidad estructural económica que influencia el desarrollo socio-económico del país y que produce dependencia comercial, particularmente con Estados Unidos de América y la Unión Europea. De ahí que los problemas de la Sierra Norte ecuatoriana (entendidas como las provincias de Pichincha, Imbabura y Carchi), en cuanto a la gestión internacional de sus negocios, se deriven de la coyuntura internacional con estos mercados en particular (ver Tabla 2). 
Tabla 2. Necesidades, problemas y soluciones en el campo de los negocios internacionales en Ecuador

\begin{tabular}{|c|c|c|}
\hline NECESIDADES & PROBLEMAS & SOLUCIONES \\
\hline $\begin{array}{l}\text { Generar conocimiento y } \\
\text { experticia pertinente en } \\
\text { negocios internacionales } \\
\text { para el mejoramiento de la } \\
\text { comercialización de bienes } \\
\text { y servicios de la pequeña y } \\
\text { grande empresa de manera } \\
\text { efectiva. }\end{array}$ & $\begin{array}{l}\text { La venta de productos primarios con } \\
\text { limitado valor agregado a precios } \\
\text { poco rentables por parte de } \\
\text { pequeños, medianos y grandes } \\
\text { productores a empresas y } \\
\text { exportadores que hacen de } \\
\text { intermediarios con escaso } \\
\text { conocimiento de negocios en } \\
\text { mercados extranjeros que generan } \\
\text { pérdidas en el largo plazo. }\end{array}$ & $\begin{array}{l}\text { Impulsar la formación de } \\
\text { profesionales en el área de } \\
\text { negocios internacionales, } \\
\text { que ayude a superar los } \\
\text { problemas de producción, } \\
\text { comercialización, y } \\
\text { distribución de productos } \\
\text { ecuatorianos no } \\
\text { tradicionales a nivel } \\
\text { internacional en el mediano } \\
\text { y largo plazo. }\end{array}$ \\
\hline $\begin{array}{l}\text { Ampliar a la oferta } \\
\text { exportable de productos no } \\
\text { petroleros de las MIPYMES } \\
\text { y de organizaciones } \\
\text { societarias del sector de } \\
\text { Economía Popular y } \\
\text { Solidaria (EPS). }\end{array}$ & $\begin{array}{l}\text { La producción de las MIPYMES y de } \\
\text { las organizaciones societarias del } \\
\text { sector de EPS para ser enviadas al } \\
\text { mercado internacional por terceros } \\
\text { con marcas personalizadas. }\end{array}$ & $\begin{array}{l}\text { Incrementar a la oferta } \\
\text { exportable de bienes y } \\
\text { servicios del Ecuador, la } \\
\text { producción de las } \\
\text { MIPYMES y de } \\
\text { organizaciones societarias } \\
\text { del sector de EPS. }\end{array}$ \\
\hline
\end{tabular}

Fuente: Elaboración propia.

Si bien, el país se mantiene en el siglo XXI en un modelo exportador de commodities donde resaltan los sectores clásicos como el minero, el petrolero, el camaronero y bananero, se pretende atender con esta propuesta la problemática relacionada con los sectores históricamente desatendidos y no tradicionales, que genera empleo y desarrollo económico en los pequeños mercados laborales del país y específicamente de las provincias de Pichincha, Imbabura y Carchi. En este sentido, los sectores descritos anteriormente presentan circunstancias que determinan la urgencia de replantear el diseño de la estructura curricular de una carrera en negocios internacionales, a la que se debe incorporar los fundamentos de la complejidad sistémica en el proceso, potenciando el campo de la investigación, vinculación y prácticas pre profesionales de forma en que se vayan planteado alternativas de solución a las problemáticas identificadas en función de los nodos reconocidos y del Plan Nacional de Desarrollo.

\subsection{Tendencias de desarrollo en relación con la evolución de la problemática identificada y la carrera de negocios internacionales en modalidad en línea}

La primera tendencia transversal de desarrollo relacionada con los negocios internacionales es la globalización. Un proceso de unificación de criterios y formas de trabajo en torno a la digitalización de los negocios y la innovación en los procesos. La globalización en su era tecnológica ha requerido una adaptación cada vez más rápida de las personas y sus perfiles profesionales para hacer frente a los desafíos administrativos y comerciales. En este sentido, la carrera de negocios internacionales se inserta en las tendencias previstas por la Organización Mundial del Comercio (2015) que resalta las habilidades a desarrollar por los profesionales del área en función del comportamiento del mercado, ahora relacionadas con la negociación de prácticas de Comercio Sur-Sur, comercio convencional y emprendimientos con valor agregado bajo el componente del e-commerce. 
La segunda gran tendencia del desarrollo es la integración mundial y regional en América Latina, la cual se está consolidando de tal forma en que el Estado ecuatoriano deba contar con los escenarios suficientes para incrementar sus relaciones comerciales internacionales y no cerrarse al proceso integracionista. Antiguas y recientes negociaciones con países tradicionales como Estados Unidos y la Unión Europea se han fortalecido por el gobierno de Lenin Moreno y Guillermo Lasso. Adicionalmente, no se ha dejado de lado los procesos de negociación iniciado con países y bloques no tradicionales para Ecuador como Turquía, Guatemala, China, Asociación Europea de Libre Comercio (EFTA), y Alianza del Pacífico. Esta última como prioridad del Ecuador por su pragmatismo comercial y alejamiento de modelos ideologizados (García, 2013, p. 48). En el ámbito multilateral, se ha dado continuidad a procesos dentro de la Organización Mundial de Comercio (OMC), la Organización Mundial de Aduanas (OMA), la Conferencia de Negocios y Desarrollo de las Naciones Unidas (UNCTAD), entre los principales.

La política económica del libre comercio en Ecuador tiene por objetivo eliminar las barreras de entrada de las importaciones y a su vez promover las exportaciones con el fin de incentivar un flujo de intercambio comercial sin restricciones (Pastrana y Gehring, 2014), lo que delinea una tercera tendencia de desarrollo internacional de los negocios basada en una apertura comercial e inserción estratégica de los negocios ecuatorianos en el mundo, una creciente recepción de inversión extranjera y una consolidación de los mercados extranjeros para productos no tradicionales (Ministerio de Relaciones Exteriores y Movilidad Humana, 2018, p. 52).

La actualidad de los países en desarrollo, entre ellos Ecuador, está marcada por una dependencia en la venta internacional de commodities en el mediano y largo plazo, así como por un creciente dinamismo de los organismos de fomento de las exportaciones e inversiones para productos innovadores en un contexto de virtualidad. El objetivo del Estado ecuatoriano se ha centrado en generar mayor valor agregado de sus productos y servicios en el marco de la construcción de una sociedad enfocada al conocimiento y el impulso de la transformación productiva desde el enfoque de cambio del patrón de especialización. Esta visión se presenta en coherencia con las tendencias globales de desarrollo económico y los campos de acción en los que el perfil del profesional puede aportar de acuerdo con las áreas académicas de los negocios internacionales principales y vigentes (ver Tabla 3). 
Tabla 3. Tendencias y campos de acción de los negocios internacionales a nivel mundial

\begin{tabular}{|c|l|l|l|}
\hline$N^{0}$ & \multicolumn{1}{|c|}{ ÁREAS } & \multicolumn{1}{|c|}{ TENDENCIAS } & \multicolumn{1}{c|}{ CAMPO DE ACTUACIÓN } \\
\hline 1 & $\begin{array}{l}\text { Comercio } \\
\text { Internacional }\end{array}$ & $\begin{array}{l}\text { La digitalización ha implicado una } \\
\text { innovación en los procesos operativos del } \\
\text { comercio. }\end{array}$ & $\begin{array}{l}\text { Comercio exterior, comercio } \\
\text { electrónico, simulación de } \\
\text { negocios. }\end{array}$ \\
\hline 2 & $\begin{array}{l}\text { Relaciones } \\
\text { Internacionales }\end{array}$ & $\begin{array}{l}\text { Las problemáticas globales conforman un } \\
\text { escenario cambiante y de transformación } \\
\text { que a su vez implica volatilidad en los } \\
\text { mercados y la ascensión de mercados } \\
\text { emergentes, sobre todo del Asia Pacífico. }\end{array}$ & $\begin{array}{l}\text { Relaciones Internacionales, } \\
\text { integración económica, } \\
\text { negociación internacional e } \\
\text { intercultural. }\end{array}$ \\
\hline 3 & $\begin{array}{l}\text { Logística } \\
\text { Internacional }\end{array}$ & $\begin{array}{l}\text { El mercado actual de transporte } \\
\text { internacional se ha desarrollado como una } \\
\text { economía de escala que ha abaratado los } \\
\text { costos de sus paquetes a un nivel } \\
\text { incomparable. }\end{array}$ & $\begin{array}{l}\text { Logística, transporte } \\
\text { internacional, operaciones del } \\
\text { comercio. }\end{array}$ \\
\hline 4 & $\begin{array}{l}\text { Finanzas } \\
\text { Internacionales }\end{array}$ & $\begin{array}{l}\text { Los efectos de la coyuntura internacional } \\
\text { han provocado una caída en los indicadores } \\
\text { bursátiles y financieros. }\end{array}$ & $\begin{array}{l}\text { Finanzas internacionales, } \\
\text { inversiones, economía } \\
\text { internacional. }\end{array}$ \\
\hline 5 & Administración & $\begin{array}{l}\text { Los mercados cada vez más } \\
\text { interconectados no solo de forma digital sino } \\
\text { también logística demandan innovación } \\
\text { administrativa. }\end{array}$ & $\begin{array}{l}\text { Administración de empresas, } \\
\text { digitalización de los negocios, } \\
\text { incubación de ideas. }\end{array}$ \\
\hline
\end{tabular}

Fuente: Elaboración propia.

A estas tendencias globales descritas, se identifican algunas propias del sector productivo de la Sierra Norte ecuatoriana como: la asociatividad comunitaria, la gestión financiera, a través de la economía popular y solidaria, y la mantención de rasgos culturales familiares sólidos, que buscan manifestarse en los productos a comercializar y en los procesos administrativos. En respuesta a dichas tendencias, la profesionalización en negocios internacionales se centra en el aprovechamiento de las nuevas herramientas teóricas, prácticas, interactivas y cibernéticas para áreas como: el comercio exterior, una temática fundamental en la comprensión teórica de los cambios en el sistema global de comercialización; las relaciones internacionales, un pilar fundamental en el entendimiento de la geopolítica global y el orden mundial en transformación; la logística internacional, responsable del abastecimiento de insumos a las industrias y de productos finales al cliente; las finanzas internacionales, un área enfocada en el análisis de las previsiones financieras y políticas; y la administración de empresas, un eje transversal de la dirección y manejo estratégico de las organizaciones.

\subsection{Articulación de las problemáticas identificadas con los objetivos, metas y políticas de los cuerpos normativos del Ecuador y la carrera de negocios internacionales en modalidad en línea}

La pertinencia de la educación nos remite a la necesidad de que ésta sea significativa para personas de distintos estratos sociales y culturales, y con diferentes capacidades e intereses, de forma que puedan apropiarse de los contenidos de la cultura, mundial y local (Blanco, 2007, pág. 43).

De ahí, que el análisis implique centrarse en conocer la cosmovisión e interés del alumnado en el marco de la normativa vigente, que se fundamenta en 3 cuerpos normativos: la Constitución Política del Ecuador (2008), la Ley Orgánica de Educación Superior del Ecuador (2018), y el Plan Nacional de Desarrollo (2017-2021). El primer documento indica en su artículo 350 que: 
El sistema de educación superior tiene como finalidad la formación académica y profesional con visión científica y humanista; la investigación científica y tecnológica; la innovación, promoción, desarrollo y difusión de los saberes y las culturas; la construcción de soluciones para los problemas del país, en relación con los objetivos del régimen de desarrollo (p. 169).

El segundo documento, la Ley Orgánica de Educación Superior del Ecuador (2018), con su carácter rector de la formación universitaria formal, menciona en su artículo 107 que:

el principio de pertinencia consiste en que la educación superior responda a las expectativas y necesidades de la sociedad, a la planificación nacional, y al régimen de desarrollo, a la prospectiva de desarrollo científico, humanístico y tecnológico mundial, y a la diversidad cultural (p. 44).

El tercer documento, el Plan Nacional de Desarrollo 2017-2021, refiere a la pertinencia educativa como la democratización del acceso a mayores oportunidades de participación en la educación superior durante las distintas fases de la vida empresarial como pilar del desarrollo económico y productivo del Ecuador (Ministerio de Producción, Comercio Exterior, Inversiones y Pesca, 2020).

En este contexto, se ha ido paulatinamente reconociendo varias modalidades de estudio para la oferta de programas de educación superior. En el año 2015 se emite por parte del Consejo de Educación Superior el Reglamento para carreras y programas académicos en modalidad en línea, a distancia y semipresenciales o de convergencia de medios, el cual, define las diferencias entre las nuevas modalidades de estudio aprobadas, y describe a la educación en línea como la:

modalidad mediada fundamentalmente por el uso de tecnologías interactivas multimedia, y entornos virtuales que organizan la interacción educativa de los actores del proceso educativo, en tiempo real o diferido a través de plataformas informáticas académicas que facultan la labor tutorial, sincrónica y asincrónica (Consejo de Educación Superior, 2015).

Los negocios internacionales aparecen como un área de la administración que se ocupa de la planificación y la transformación empresarial hacia la internacionalización. Se entiende como:

el proceso por el cual una empresa participa de la realidad de la globalización, es decir, la forma en que la empresa proyecta sus actividades, total o parcialmente, a un entorno internacional y genera flujos de diversos tipos (comerciales, financieros y de conocimiento) entre distintos países (Araya, 2009, p. 18).

La carrera de negocios internacionales de la Universidad de Otavalo en modalidad en línea responde a "la intencionalidad de encarar un proceso de desarrollo que conduzca a un fortalecimiento de la organización, en el que se incorpora nueva tecnología más moderna" (Schlemenson, 1998, pág. 52) y propende al desarrollo del talento humano con características de una formación técnica y pertinente, con la responsabilidad de crear profesionales competentes que respondan a las necesidades de la sociedad ecuatoriana en el ámbito del intercambio de productos a nivel internacional. La relación entre las problemáticas y necesidades identificadas anteriormente con la normativa vigente es clara y directa. El marco normativo ecuatoriano se erige como una fortaleza para nuevas propuestas de carácter educativo y empresarial. Su comprensión y la articulación con las políticas públicas son las que requieren refuerzo para poder llegar al éxito empresarial de forma en la que se solucione de forma práctica los requerimientos de la sociedad.

Lograr que el aprendizaje sea pertinente para todos exige una transformación profunda de las prácticas educativas, transitando desde una pedagogía de la homogeneidad hacia una pedagogía de la diversidad, aprovechando ésta como una oportunidad para enriquecer los procesos de enseñanza y aprendizaje, y optimizar el desarrollo personal y social (Blanco, 2007). 
Es así como a partir de una revisión detallada de los insumos del presente estudio de pertinencia se plantea la misión y la visión de la nueva carrera que pretende alinear sus objetivos, su objeto de estudio y las áreas de desempeño con las metas estipuladas en los cuerpos normativos, instrumentos de planificación y las estrategias sectoriales en Ecuador.

El nuevo Código Orgánico de la Producción, Comercio e Inversiones (2018) establece la importancia de formar profesionales en la promoción de las exportaciones, fomentando la producción nacional, que generen un impacto directo en el aumento de plazas de trabajo de dependencia y en especial de trabajo autónomo en comercio exterior. En el libro V del Código, se hace referencia a la facilitación aduanera, no solo como un procedimiento aduanero normativo sino como un eje estratégico de recaudación de impuestos y desarrollo con base en los pilares fundamentales de transferencia de información, digitalización, y publicidad.

Ecuador proyecta su estructura productiva hacia la superación de la exportación de materias primas, pues esto ha reproducido desigualdades regionales e internacionales en términos de conocimiento, innovación y desarrollo tecnológico. El objetivo del país es formar una economía basada en la prestación de servicios y en la generación de bienes con valor agregado, cimentada en una producción limpia y sustentable, bajo parámetros de justicia social e intergeneracional y que aporte al desarrollo de Ecuador en condiciones de equidad y solidaridad (Plan Nacional de Desarrollo, 2017, p.12). La infraestructura productiva, la tecnología y el conocimiento son elementos fundamentales para fortalecer los circuitos comerciales solidarios, los encadenamientos productivos y las economías populares y solidarias capaces de dinamizar la competitividad sistémica del territorio nacional, conforme al objetivo 5 del Eje 2, respecto a "impulsar la productividad y competitividad para el crecimiento económico sostenible" (Plan Nacional de Desarrollo, 2017, p. 82-83). En la Tabla 4 se referencian las políticas y metas de dicho objetivo frente a la propuesta de carrera de Negocios Internacionales.

La carrera de Negocios Internacionales de la Universidad de Otavalo, en alineación con las políticas 5.2, 5.4, 5.6 y 5.9 del objetivo 5 propenderá a la formación técnica y pertinente de profesionales que respondan a las necesidades identificadas de la sociedad ecuatoriana, con particular énfasis de las 3 provincias de la Sierra Norte ecuatoriana (Pichincha, Imbabura y Carchi).

La propuesta curricular se centra en atender el intercambio internacional de bienes y sobre todo servicios (como las artesanías y el turismo). Los profesionales por tanto buscarán, con pensamiento crítico, dinamizar la economía sumándose a la cadena de valor para mejorar las estructuras societarias ecuatorianas con visión de competitividad interna y externa, lo que permita la satisfacción de la exigente demanda en los mercados internacionales. 
Tabla 4. Políticas y metas del objetivo 5 del eje 2 del PND

\begin{tabular}{|c|c|}
\hline \multicolumn{2}{|c|}{$\begin{array}{l}\text { Objetivo } 5 \text { del Plan Nacional para el Desarrollo } \\
\text { Impulsar la productividad y competitividad para el crecimiento económico sostenible de } \\
\text { manera redistributiva y solidaria }\end{array}$} \\
\hline Políticas & Metas \\
\hline $\begin{array}{l}\text { 5.2. Promover la productividad, competitividad y calidad } \\
\text { de los productos nacionales, como también la } \\
\text { disponibilidad de servicios conexos y otros insumos, } \\
\text { para generar valor agregado y procesos de } \\
\text { industrialización en los sectores productivos con } \\
\text { enfoque a satisfacer la demanda nacional y de } \\
\text { exportación. }\end{array}$ & \multirow{3}{*}{$\begin{array}{l}\text { Disminuir el índice de concentración de } \\
\text { exportaciones no petroleras por } \\
\text { producto de } 0,1252 \text { a } 0,0799 \text { a } 2021 \text {. } \\
\text { Aumentar el valor de las exportaciones } \\
\text { no tradicionales de US\$ } 295 \text { a US } \$ 375 \\
\text { per cápita a } 2021 \text {. } \\
\text { Mejorar el resultado de la balanza } \\
\text { comercial no petrolera a } 2021 \text {. } \\
\text { Incrementar la Inversión Directa del } \\
\text { sector productivo en relación al al } \\
\text { Producto Interno Bruto No Petrolero, en } \\
\text { condiciones que garanticen el ingreso } \\
\text { de divisas, procesos limpios de } \\
\text { producción, transferencia de tecnología } \\
\text { y generación de empleo a } 2021 \text {. }\end{array}$} \\
\hline $\begin{array}{l}\text { 5.4. Incrementar la productividad y generación de valor } \\
\text { agregado creando incentivos diferenciados al sector } \\
\text { productivo, para satisfacer la demanda interna, y } \\
\text { diversificar la oferta exportable de manera estratégica. }\end{array}$ & \\
\hline $\begin{array}{l}\text { 5.6. Promover la investigación, la formación, la } \\
\text { capacitación, el desarrollo y la transferencia } \\
\text { tecnológica, la innovación y el emprendimiento, la } \\
\text { protección de la propiedad intelectual, para impulsar el } \\
\text { cambio de la matriz productiva mediante la vinculación }\end{array}$ & \\
\hline entre el sector público, productivo y las universidades. & \multirow{2}{*}{$\begin{array}{l}\text { Mejorar el Índice de Productividad } \\
\text { Nacional a } 2021 \text {. }\end{array}$} \\
\hline $\begin{array}{l}\text { 5.9. Fortalecer y fomentar la asociatividad, los circuitos } \\
\text { alternativos de comercialización, las cadenas } \\
\text { productivas, negocios inclusivos y el comercio justo, } \\
\text { priorizando la Economía Popular y Solidaria, para } \\
\text { consolidar de manera redistributiva y solidaria la } \\
\text { estructura productiva del país. }\end{array}$ & \\
\hline
\end{tabular}

Fuente: Plan Nacional para el Desarrollo, 2017-2021.

\section{RESULTADOS}

\subsection{Análisis nacional de la oferta del programa de negocios internacionales en modalidad en línea}

La oferta académica de las universidades en el Ecuador ha pasado por cambios entre 2010 y 2020, en especial a partir del 2015, que se entregó por parte de la Asamblea Nacional el Proyecto de ley de Cierre de Universidades, en respuesta a los resultados del Consejo de Evaluación, Acreditación, y Aseguramiento de la Calidad de la Educación Superior (CEAACES) de las evaluaciones desarrolladas entre el 2012 y 2013, que culminó con el cierre de 14 universidades. Se optó por una categorización de las universidades, que conllevó a evaluaciones constantes y a una transformación de la Educación Superior en el Ecuador, enmarcada en responder no solo al contexto nacional sino a considerar estándares de nivel internacional. Dentro de los cambios estructurales de la Educación Superior en el Ecuador, destaca la transformación del CONESUP en la SENESCYT en 2010, por medio de la Ley de Educación aprobada en ese año. El nuevo organismo promueve la internacionalización de la educación superior por medio de becas y reconocimiento de títulos de ecuatorianos que retornan al país, y extranjeros que laboran actualmente en el Ecuador. 
Los cambios producidos tienen que ver con la propuesta del modelo de universidad, las misiones de enseñanza e investigación están supeditadas a una tercera misión: la universidad instrumental, productivista y de corte empresarial, funcional al mercado, al Plan Nacional de Desarrollo y al Buen Vivir que es el instrumento del Gobierno Nacional para articular las políticas públicas con la gestión y la inversión pública (Cóndor, 2017).

La oferta académica universitaria en el Ecuador presenta un total de 2.159 carreras de tercer nivel, las cuales pueden ser cursadas en instituciones públicas y privadas. Para finales del año 2019, en Ecuador existían 30 universidades y escuelas politécnicas públicas; 26 particulares, 85 institutos superiores técnicos, tecnológicos y conservatorios públicos; y 92 particulares (SENESCYT, 2019). De las 233 Instituciones de Educación Superior (IES) que ofertan carreras de tercer nivel, se han escogido 56 universidades que emiten títulos de pregrado con nivel de licenciatura. De ellas, 47 universidades ofertan la carrera de administración de empresas (21 públicas y 26 privadas); y 9 la carrera de Comercio Exterior (5 públicas y 4 privadas). De las 47, existe un total de 10 universidades que ofrecen programas de negocios internacionales ( 1 pública y 9 privadas), todas ellas en modalidad presencial, solamente la Universidad Internacional del Ecuador (UIDE) oferta un programa en modalidad en línea (ver Tabla 5).

En este contexto, se evidencia que la Pontificia Universidad Católica del Ecuador oferta programas de Negocios Internacionales en varias sedes: Manabí, Pichincha, Esmeraldas e Imbabura; la Universidad del Pacífico en: Pichincha y Guayaquil; la Universidad Internacional del Ecuador en: Guayaquil, Loja y Pichincha; y la Universidad Técnica Equinoccial en: Pichincha y Santo Domingo.

Tabla 5. Oferta académica de la carrera de negocios internacionales en Ecuador, por modalidad al 2020

\begin{tabular}{|c|c|c|c|c|c|}
\hline \multirow[b]{2}{*}{$\mathbf{N}^{\circ}$} & \multirow[b]{2}{*}{ UNIVERSIDAD } & \multicolumn{2}{|c|}{ MODALIDAD } & \multirow[b]{2}{*}{ UBICACIÓN } & \multirow[b]{2}{*}{ NIVEL } \\
\hline & & $\begin{array}{l}\text { EN } \\
\text { LÍNEA }\end{array}$ & PRESENCIAL & & \\
\hline 1 & PUCE & & sí & $\begin{array}{c}\text { Manabí / Pichincha / } \\
\text { Esmeradas / } \\
\text { Imbabura }\end{array}$ & 9 \\
\hline 2 & UDLA & & sí & Pichincha & 8 \\
\hline 3 & $\begin{array}{l}\text { Universidad Católica } \\
\text { Santiago de Guayaquil } \\
\text { (UCSG) }\end{array}$ & & sí & Guayas & 9 \\
\hline 4 & Universidad de Guayaquil & & sí & Guayas & 8 \\
\hline 5 & Universidad Hemisferios & & sí & Pichincha & 8 \\
\hline 6 & Universidad del Pacifico & & sí & Guayas / Pichincha & 10 \\
\hline 7 & $\begin{array}{l}\text { Universidad Internacional del } \\
\text { Ecuador UIDE }\end{array}$ & $\mathrm{SI}$ & sí & $\begin{array}{l}\text { Guayas / Pichincha / } \\
\text { Loja }\end{array}$ & 8 \\
\hline 8 & $\begin{array}{l}\text { Universidad Particular } \\
\text { Internacional SEK }\end{array}$ & & sí & Pichincha & 8 \\
\hline 9 & $\begin{array}{l}\text { Universidad Tecnológica } \\
\text { ECOTEC }\end{array}$ & & sí & Guayas & 9 \\
\hline 10 & $\begin{array}{l}\text { Universidad Tecnológica } \\
\text { Equinoccial UTE }\end{array}$ & & sí & $\begin{array}{l}\text { Pichincha / Santo } \\
\text { Domingo }\end{array}$ & 8 \\
\hline
\end{tabular}

Fuente: Elaboración propia. 


\subsection{Análisis de la demanda a nivel nacional del programa de negocios internacionales en modalidad en línea}

La caracterización de este apartado se remite a 3 ejes fundamentales: conocer la demanda de empleadores en general, de los estudiantes de tercer año de bachillerato, y del mercado potencial, circunscrito a personas económicamente activa, con empleo, entre 18 y 44 años, que no hayan obtenido su título profesional. El diagnóstico de la demanda se ha realizado a través de una investigación de campo compuesta por 4 fases, para las que se han diseñado y levantado encuestas, considerando la cercanía geográfica de las poblaciones investigadas pertenecientes a las provincias de Pichincha, Imbabura y Carchi, que componen la Sierra Norte ecuatoriana. Se ha utilizado medios físicos (para el levantamiento de información en la fase 1, 2 y 3) así como medios digitales (para la fase 4).

Primera fase. - En esta primera fase se aplica 675 encuestas dirigidas a propietarios de establecimientos comerciales en la Sierra Norte del Ecuador que no pudieron llevar una carrera profesional en un aula tradicional, por ser personas de edad avanzada, personas con exhaustivos horarios de trabajo, personas que cuidan de su hogar y de su(s) hijo(s), personas que viven en localidades alejadas. Las 675 personas respondieron a 2 preguntas sobre la necesidad de formación en negocios internacionales y sobre su preferencia de modalidad de estudios.

Gráfico 1. Necesidad de formación

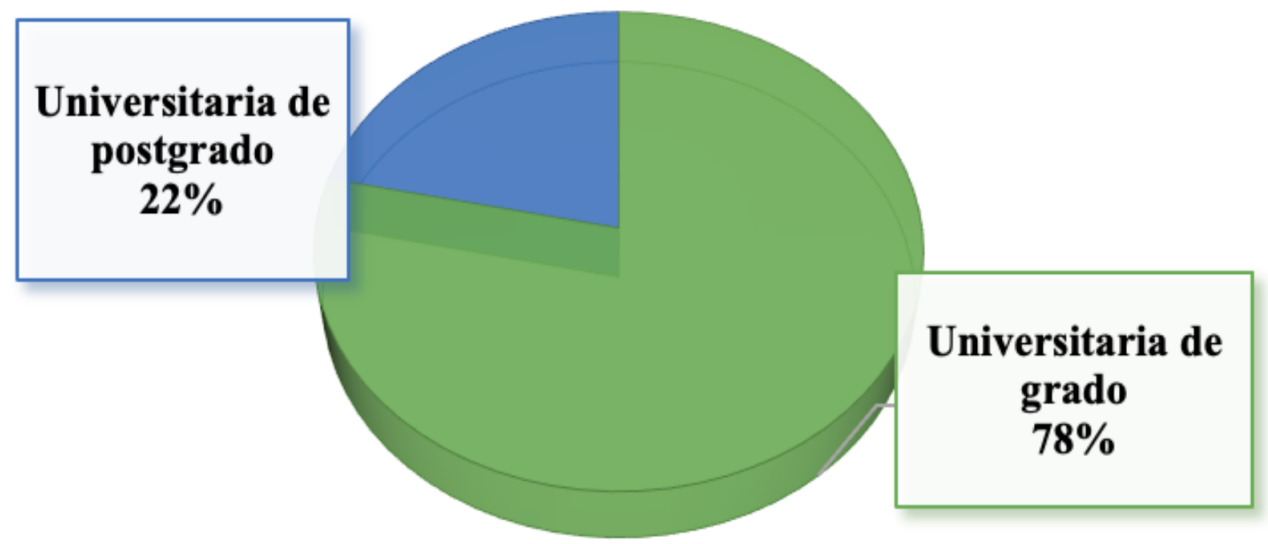

Fuente: Elaboración propia.

Los resultados obtenidos de la primera pregunta confirman la hipótesis de que existe una latente necesidad de formación profesional por parte de los empresarios y propietarios de negocios en Pichincha, Imbabura y Carchi. Esta demanda insatisfecha se respalda por un 78\% de respuestas afirmativas para programas de grado, lo que representa 526 personas que requieren el servicio. El dato se contrapone ante el 22\% de los encuestados (119) que han respondido que requieren formación pero en programas de posgrado (ver Gráfico 1).

El 46\% de los encuestados (310 personas) tienen una inclinación por el modo de estudio semipresencial, el 31\% (209 personas) por la modalidad presencial y un 23\% (156) por la en línea. Estos datos reflejan la importancia de la utilización de herramientas virtuales y digitales para responder 
a un grupo importante de la población que requiere aprovechar los recursos en el estudio no presencial (ver Gráfico 2).

Gráfico 2. Modalidad de estudios

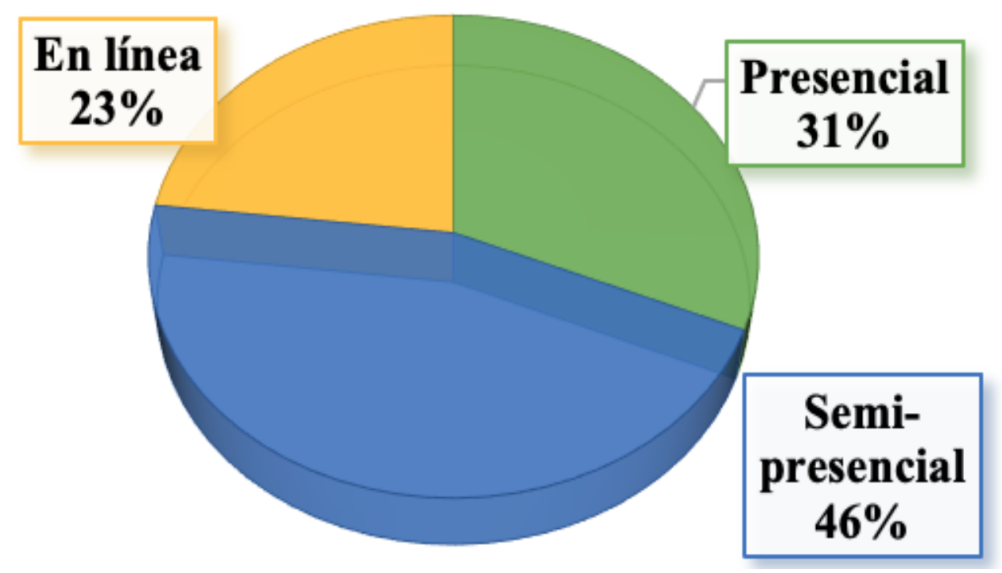

Fuente: Elaboración propia.

Segunda fase. - Se ha aplicado 584 encuestas a estudiantes de tercer año de bachillerato de colegios públicos y privados del Ecuador, cuyas respuestas a las 2 preguntas realizadas sobre modalidad de estudios y carreras de interés, se detallan a continuación.

Gráfico 3. Modalidad de estudios preferiría para continuar sus estudios universitarios

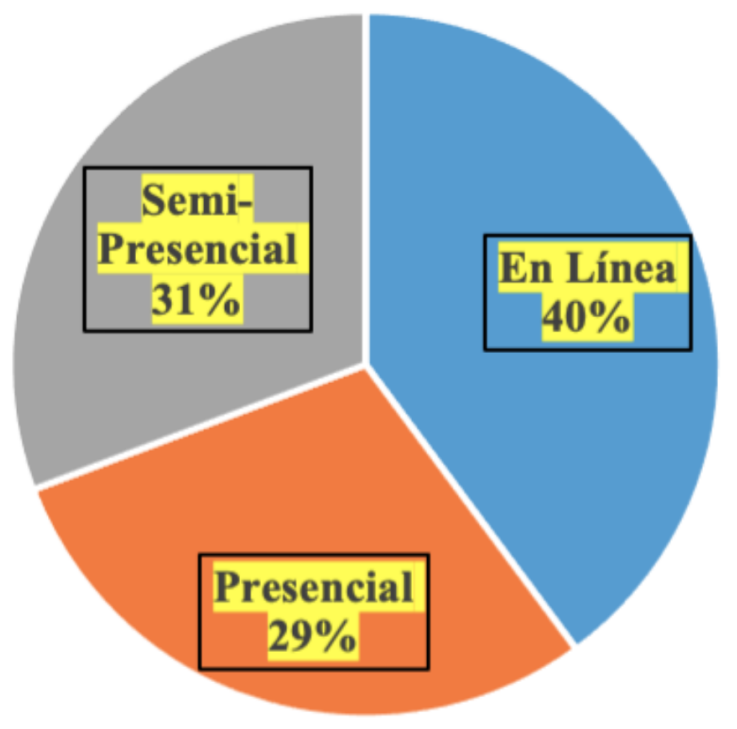

Fuente: Elaboración propia.

De las 584 encuestas planificadas, 569 estudiantes contestaron esta pregunta. Se encontró que del total registrado, el $40 \%$ (227) de estudiantes encuestados prefiere la modalidad en línea, pues en sus comentarios señalan que esta modalidad les permitiría trabajar y estudiar al mismo tiempo; el 31\% (175) tiene preferencia por la modalidad semi-presencial, de igual forma por la versatilidad 
que ofrece en la disposición del tiempo, mientras que solo un 29\% (167) prefiere una educación completamente presencial. Debajo se presenta su elección respecto al programa de estudios dentro del campo amplio de la Administración (ver Gráfico 3).

Gráfico 4. Carrera preferida para continuar los estudios universitarios

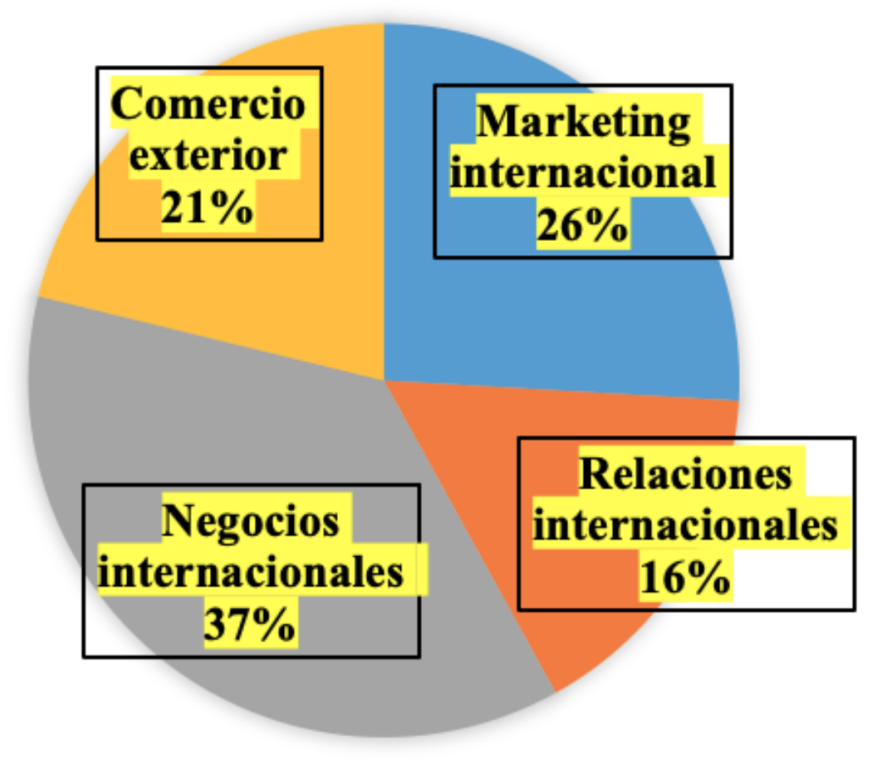

Fuente: Elaboración propia.

A esta pregunta respondieron 467 estudiantes. 117 ignoraron la pregunta (20\%), puesto que manifestaron no estar interesados en carreras del área empresarial. Del total levantado, el $37 \%$ (172) de los bachilleres encuestados en las provincias de Pichincha, Imbabura y Carchi se inclinan por la carrera de negocios internacionales, la encuentran novedosa y la vinculan con oportunidades de trabajo en el país, así como en mercados internacionales. La carrera de marketing internacional es la segunda más representativa, con una acogida del 26\% (121); los porcentajes menores restantes del 16\% (75 personas) y el 21\% (99) corresponde a las carreras de relaciones internacionales y comercio exterior respectivamente (ver Gráfico 4).

Tercera fase. - Se han aplicado 358 encuestas sobre 4 preguntas, las cuales han sido direccionadas a personas y propietarios de empresas con actividades relacionada con el comercio internacional. Las preguntas se han enfocado en cuestiones como frecuencia, importancia, dificultad, interés de actividades relacionadas con los negocios internacionales. 


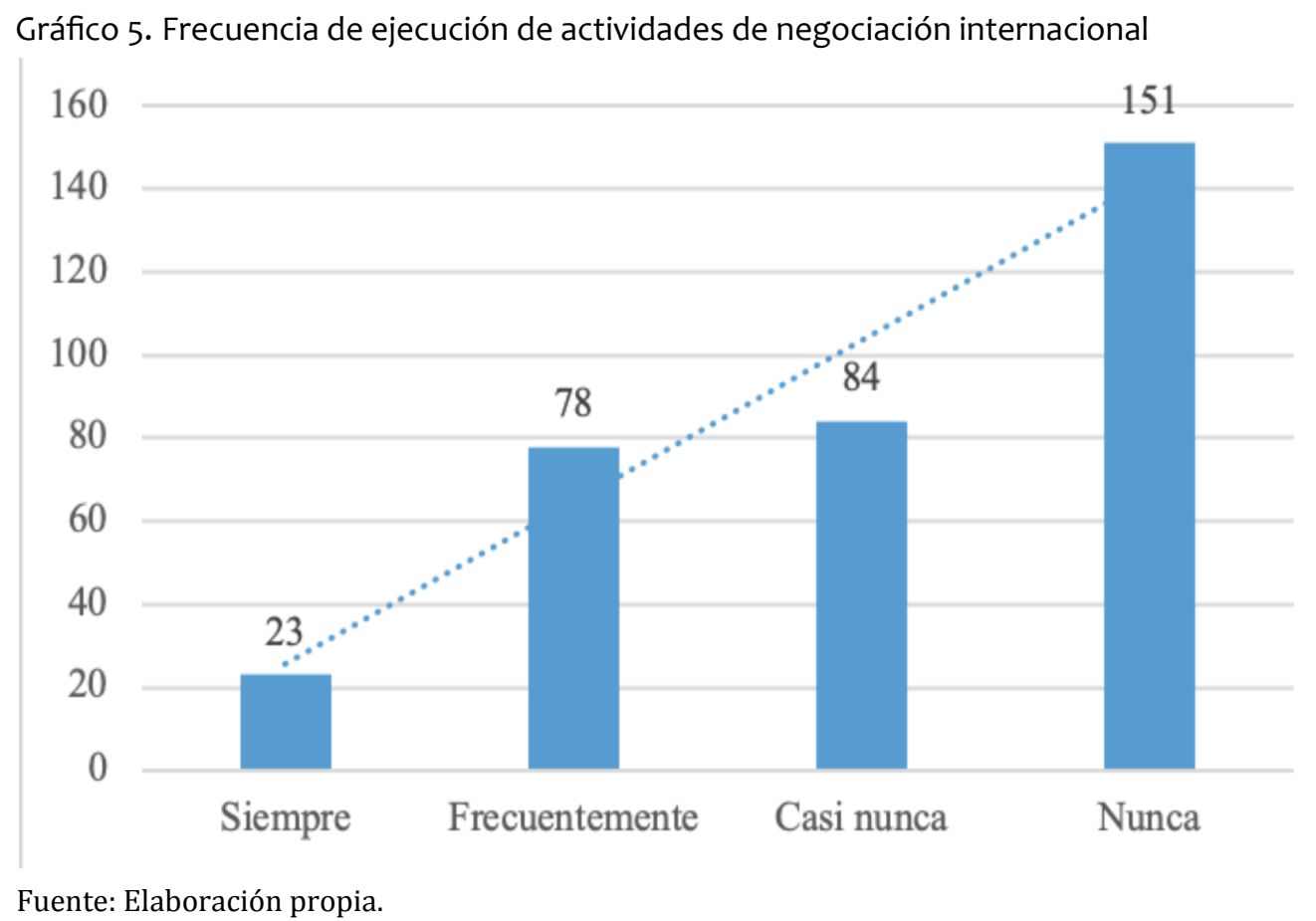

De las 358 encuestas, 22 personas no respondieron la encuesta, lo que significa un 6,14\% del total planificado. De las 336 encuestas respondidas, 23 personas $(6,42 \%)$ indican que siempre realizan negociaciones internacionales, $78(21,78 \%)$ que las realizan frecuentemente, $84(23,46 \%)$ mencionan que casi nunca realizan actividades de negociación internacional, y 151 (42,17\%) entrevistados mencionan que nunca han realizado negociaciones internacionales. En total, 101 personas $(28 \%)$ de la muestra informa que realiza actividades de relacionamiento internacional con efectos comerciales en la organización, un dato representativo (ver Gráfico 5).

Gráfico 6. Dificultad para conseguir profesionales en el área de negocios internacionales

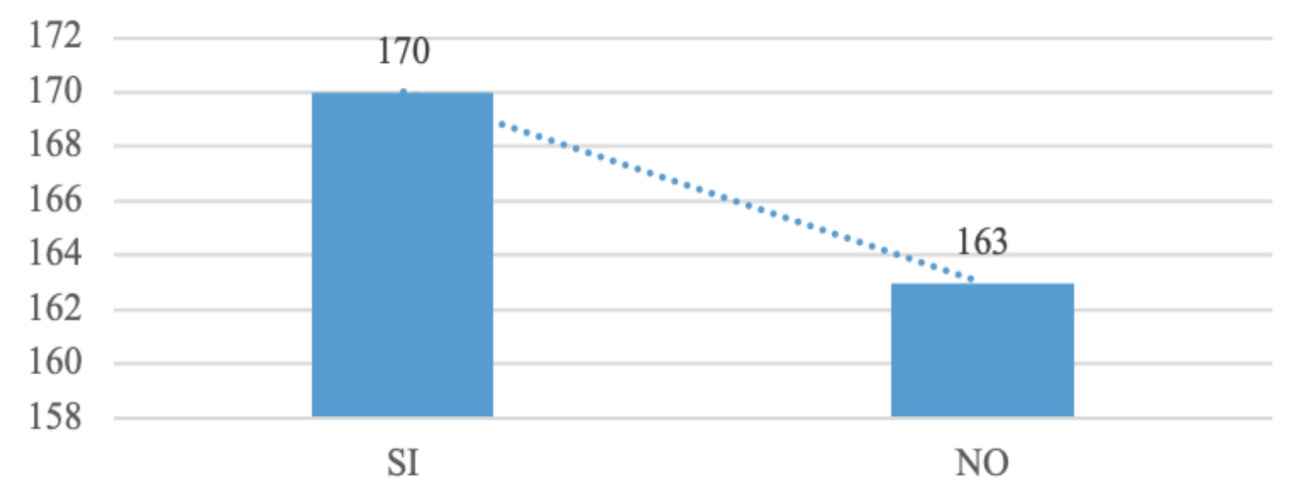

Fuente: Elaboración propia.

Se consultó si han tenido alguna dificultad para conseguir profesionales en el área de negocios internacionales. De las 358 encuestas, 25 personas no la respondieron, una cifra igual al 7,69\%. En total 333 (93\%) respondieron a la pregunta, 170 personas indicaron sí han tenido alguna dificultad, lo que representa el 47,48\%, mientras que 163 manifestaron que no, lo que representa el 45,53\%. 
Una mayoría requiere el perfil de profesionales en negocios y no lo encuentra fácilmente (ver Gráfico 6).

Gráfico 7. Interés en que el personal de la empresa se forme en el campo de los negocios internacionales

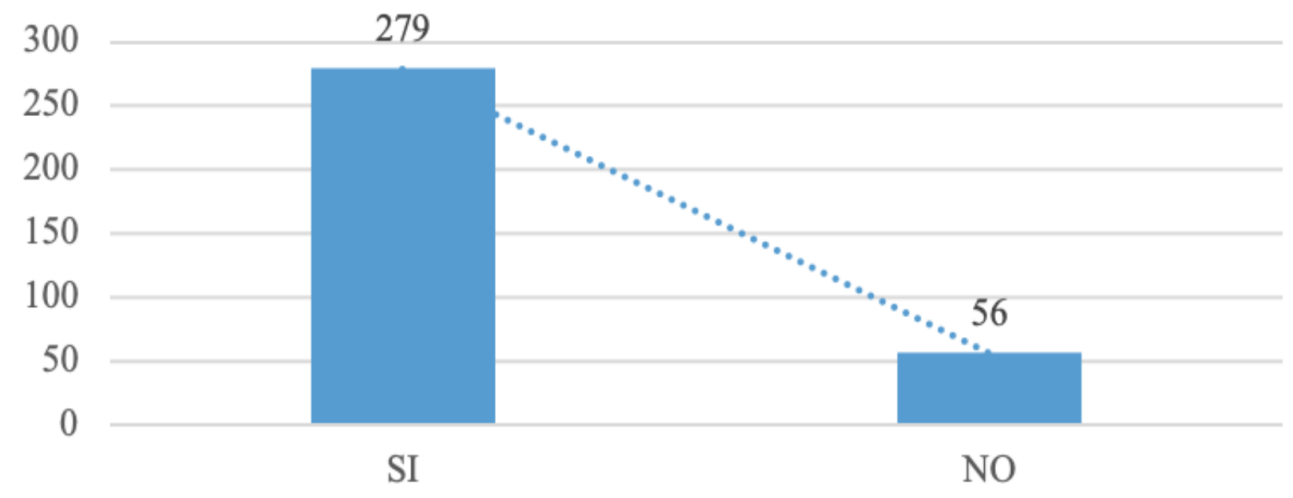

Fuente: Elaboración propia.

A esta pregunta la ignoraron 23 personas (6,42\%). 335 de los 358 planificados encuestar la respondieron. Se consultó si estaría interesado en que su personal que labora en su empresa se forme en el campo de los negocios internacionales, ante lo que se obtuvo que 279 respondieron afirmativamente $(77,93 \%)$, mientras que 56 respondieron de forma negativa, lo que representa el 15,64\% (ver Gráfico 7).

Esta pregunta fue ignorada por 20 personas (5,58\%). 338 de los 358 planificados encuestar la respondieron. Del total levantado, 293 encuestados $(81,84 \%)$ respondieron que es necesario el conocimiento de la negociación internacional en sus actividades, mientras que 45 personas (15\%) dijeron que no era importante conocimientos en esta área, lo que demuestra un claro interés de los empresarios en el perfil profesional del programa (ver Gráfico 8).

Gráfico 8. Opinión respecto de la importancia de los negocios internacionales para la empresa

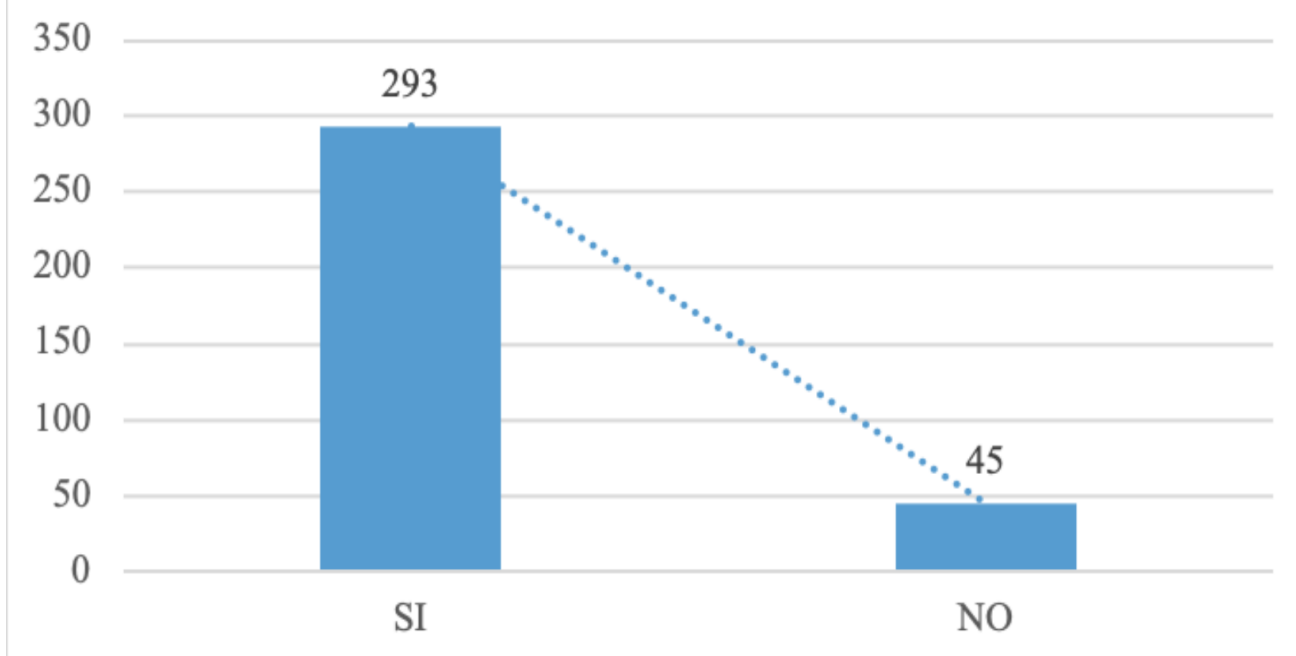

Fuente: Elaboración propia. 
Cuarta fase. - A nivel nacional, se ha aplicado una encuesta en línea a 222 personas que no han terminado sus estudios universitarios y que ejercen actividades administrativas, principalmente en el área de los negocios internacionales y del comercio exterior. El instrumento consta de 3 preguntas.

Para la muestra, se han considerado un total de 7.787.896 personas pertenecientes al grupo de la Población Económicamente Activa (PEA) del Ecuador. Con base en el criterio de empleabilidad plena, se segmentó el valor llegando a 3.481.189 (44,7\%) personas. Sin embargo, con base en criterio de edad promedio en la que se inicia estudios universitarios, de 18 a 44 años, se obtuvo un universo de 1.573.497 personas. De este número se discriminó por nivel de instrucción utilizando un muestreo estratificado, quienes siendo bachilleres realizan una actividad en el campo profesional del comercio, alojamiento, y transporte, llegando a una muestra de 222 individuos, que conforman un grupo representativo del universo descrito (INEC, 2020, p.9).

La pregunta 1 aborda el interés en profesionalizarse de parte de los encuestados en el campo de la administración y negocios internacionales, mientras que la pregunta 2 cuestiona la intención de seguir un programa de estudio para la titulación de licenciatura en la Universidad de Otavalo en modalidad en línea. La pregunta 3, por su parte busca conocer el aspecto más valorado por el estudiante a la hora de seleccionar una opción académica en la modalidad en línea.

El grupo objetivo segmentado son los bachilleres sin título profesional de entre 18 y 44 años que se encuentran en las provincias de Esmeraldas, Carchi, Sucumbíos, Pichincha, Guayas, Manabí y que están trabajando en los sectores económicos relacionados con el comercio y la administración. En total, se buscó obtener 222 respuestas. Los resultados obtenidos se presentan a continuación.

Gráfico 9. Interés en cursar la Licenciatura en Negocios Internacionales en la Universidad de Otavalo, modalidad en línea

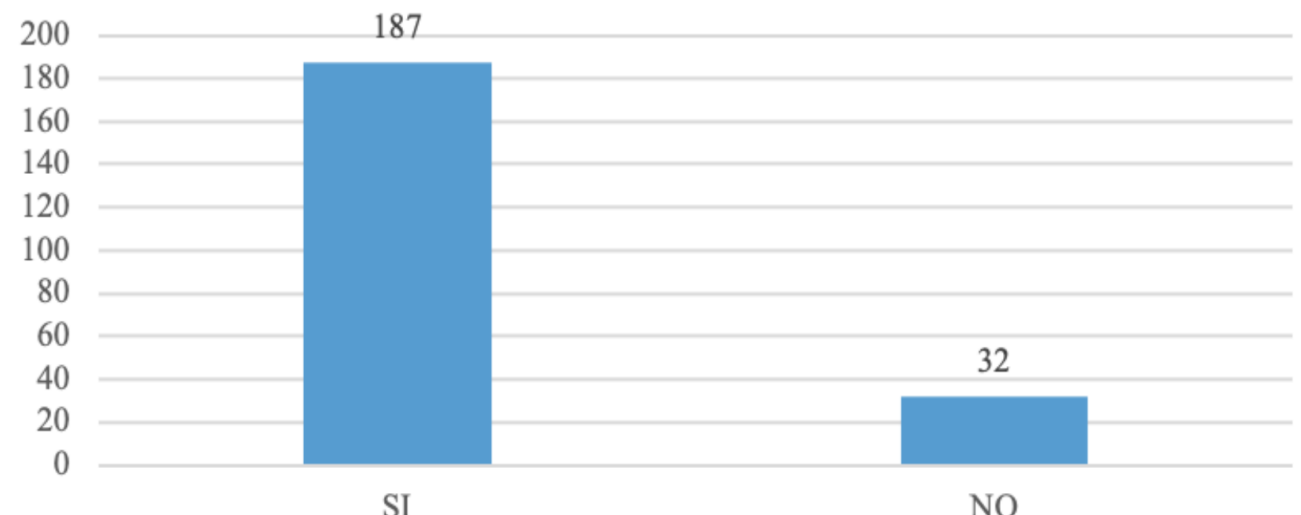

Fuente: Elaboración propia.

Del total de las 222 encuestas, se obtuvo respecto de la primera pregunta que un 84\% (187 personas) está interesado en cursar el programa de Licenciatura en negocios internacionales en la modalidad en línea en la Universidad de Otavalo. Por otra parte, se demuestra que el 14\% (32) no están interesados en hacerlo (ver Gráfico 9).

De los 222 encuestados, se obtuvo que el 19,36\% (43) se inclina por la gerencia de negocios, el 23,87\% (53) por el comercio internacional, el 13,96\% (31) por las relaciones internacionales, mientras que el 10,81\% (24) en finanzas internacionales, así como el 16,21\% (36) en negociación 
internacional, y el 15,76\% (35) en marketing internacional. Se observa que la demanda se inclina por las especializaciones en comercio y gerencia de negocios (ver Gráfico 10).

Gráfico 10. Área de estudio en la que le interesaría desarrollarse profesionalmente con la Carrera de Negocios Internacionales, modalidad en línea

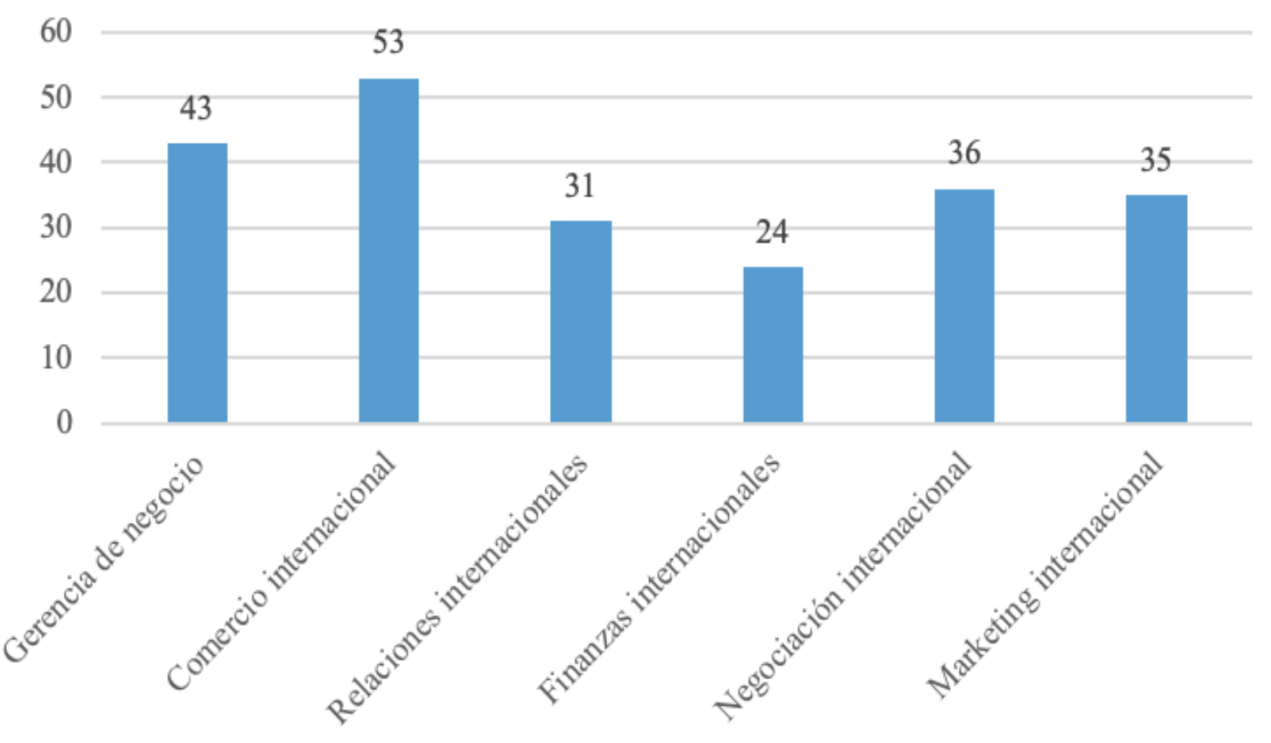

Fuente: Elaboración propia.

De la tabla de resultados, se puede observar que de 222 (100\%) encuestas aplicadas, el 49\% (109) considera importante la flexibilidad del tiempo al momento de preferir la modalidad en línea. El 17,56\% (39) valora además de forma importante la utilidad de un entorno virtual, mientras que un $9,90 \%$ (22) tienen al rubro de tutor personalizado como una ventaja de la modalidad, Finalmente, tanto el material de estudio como los profesores internacionales representan un 11,71\% (26) de las opciones más importantes (ver Gráfico 11). 
Gráfico 11. Aspecto más valorado de una carrera en modalidad en línea

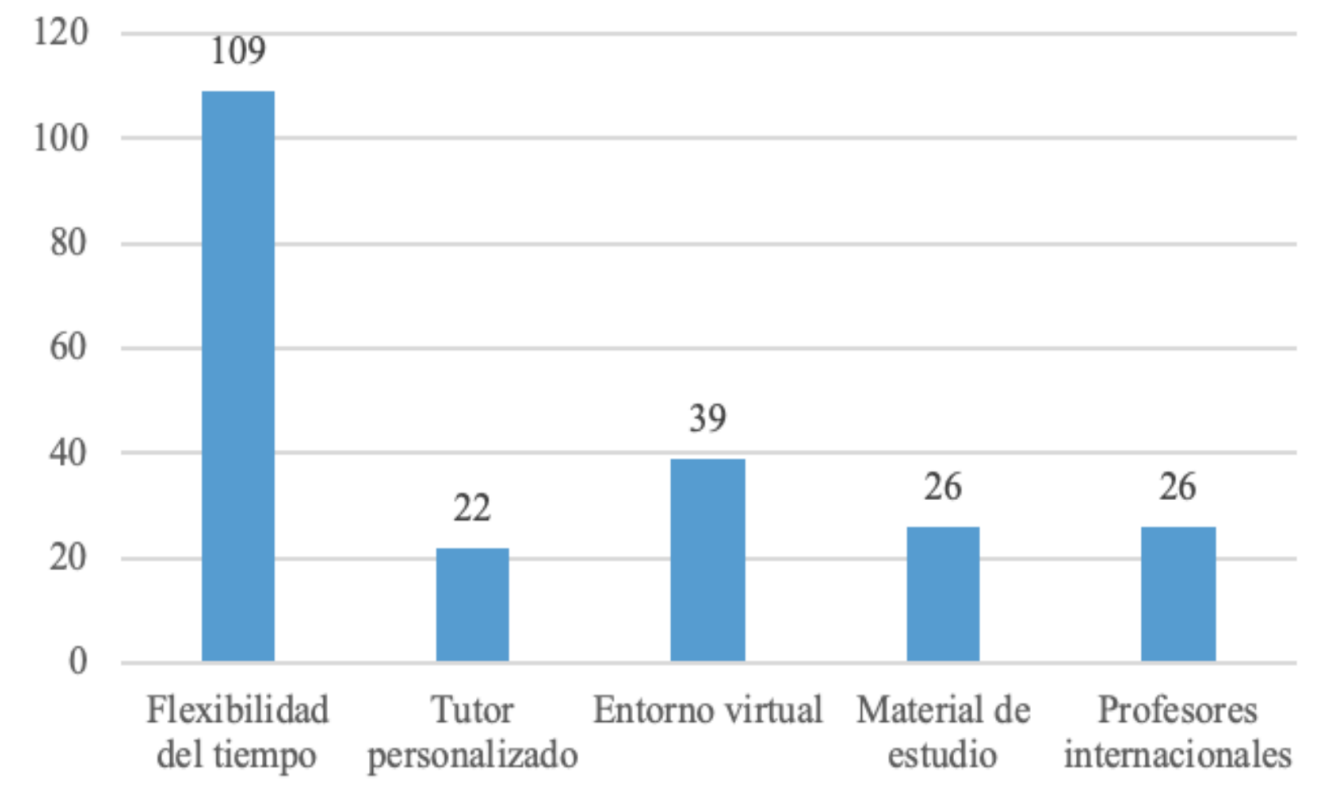

Fuente: Elaboración propia.

\section{CONCLUSIONES}

Se concluye en términos generales que se ha logrado analizar los 4 componentes clave planificados en el trabajo, en torno a las necesidades y problemáticas de los negocios internacionales, las tendencias de desarrollo vinculadas con la evolución de la problemática identificada, así como con la articulación de la propuesta con los objetivos, metas y políticas de los cuerpos normativos del país y con el estudio de mercado para el programa.

A partir de los resultados obtenidos en el presente estudio, se concluye que el diseño de un programa de negocios internacionales modalidad en línea por parte de la Universidad de Otavalo es altamente pertinente para su implementación en Ecuador en 2020, principalmente debido a que la propuesta puede ayudar a resolver tensiones y problemas relacionados con la gestión de los negocios en las áreas de comercio internacional, relaciones internacionales, logística internacional, finanzas internacionales y administración. Las soluciones planteadas por el programa se centran en la formación de profesionales multidisciplinarios, con conocimiento en producción, comercialización y distribución, con herramientas actuales y digitales que les permitan mejorar el desempeño de las MIPYMES ecuatorianas.

Se concluye que la carrera de negocios internacionales es relevante actualmente frente a las tendencias de desarrollo económico mundial como: la globalización digital de las actividades empresariales, la ascendente integración regional del Ecuador y la apertura comercial e inserción estratégica de los negocios, ante las que demuestra ser útil porque contribuye al mejoramiento del desempeño de las relaciones internacionales, de la actuación política, social y comercial de las pymes ecuatorianas así como en su especialización en productos y servicios donde tienen una mayor potencialidad y efectividad productiva como el sector artesanal y el turismo.

La carrera de negocios internacionales aporta con la consecución de los objetivos establecidos en el Plan Nacional de Desarrollo, así como con las directrices del Código Orgánico de la Producción, 
Comerio Exterior e Inversiones en respeto de los derechos garantizados por la Constitución y la Ley de Educación Superior vigentes.

Se concluye que los avances tecnológicos, el acceso simplificado a la información y la digitalización en la comunicación han transformado el escenario de los procesos mundiales en la educación superior, lo que ha implicado una constante mejora de los procesos de enseñanzaaprendizaje y la adaptación a las modalidades de educación virtual por parte de las instituciones de educación superior, entre ellas las de la Universidad de Otavalo, que con su programa de Licenciatura en negocios internacionales busca ofrecer programas académicos versátiles y adaptados a su entorno.

Se demuestra en el trabajo que la propuesta es pertinente ya que existe una limitada oferta de un producto similar en la modalidad de estudio analizada por parte de otros centros educativos del Ecuador (de los 47 centros de estudio, 9 privados y solo 1 público). Adicionalmente, se identificó una demanda insatisfecha para el programa propuesto en negocios internacionales demostrada por el interés de los estudiantes bachilleres, así como de personas económicamente activas entre 18 y 44 años sin título profesional; en el primer caso, 40\% de encuestados está interesado en continuar sus estudios de pregrado en modalidad en línea mientras que en el segundo caso 84\%. De este último dato, el 49\% prefiere un programa de negocios internacionales en modalidad en línea, porque les permite trabajar y estudiar al mismo tiempo.

Del estudio de mercado se resalta que el 82\% de empleadores destacan la importancia de los negocios internacionales para su gestión comercial. De ahí que la propuesta se erija como una oportunidad de desarrollo económico, con un nivel aceptable de empleabilidad en microempresas que requieren la contratación del perfil profesional de negocios internacionales.

\section{REFERENCIAS BIBLIOGRÁFICAS}

Araya, A. (2009). El proceso de internacionalización de empresas. TEC Empresarial. Recuperado de: https:// www.researchgate.net/publication/43950302_El_Proceso_de_Internacionalizacion_de_Empresas

Banco Mundial (1 de junio de 2020). Global Economic Prospects [Archivo PDF]. World Bank Group. Recuperado de https://www.bancomundial.org/es/publication/global-economic-prospects

Berhein, C. (2011). La educación superior frente a los desafíos contemporáneos [Memorias del evento]. Lección Inaugural del año académico 2011 en la Universidad Centroamericana. Recuperado de https://www.unl.edu.ar/iberoextension/dvd/archivos/panelistas/ponencia_carlos_tunnermann_ berheim.pdf

Blanco, R. (29 y 30 de marzo de 2007). Educación de calidad para todos: un asunto de derechos humanos [Memorias del evento]. Documento de discusión sobre políticas educativas en el marco de la II Reunión Intergubernamental del Proyecto Regional de Educación para América Latina y el Caribe.

Bonilla, A. (5 y 6 de junio de 2019). Procesos Educativos y desatinos de la educación superior [Memorias del evento]. Jornadas Repensando la Educación Superior en Ecuador, América Latina y El Caribe: a 100 años de la Reforma Universitaria de Córdoba. CIESPAL-SENESCYT

CEPAL (2020). Encontrar los efectos cada vez mayores del COVID-19 para una reactivación con igualdad: nuevas proyecciones (Informe No. 5). Informe especial sobre la evolución y los efectos de la pandemia del COVID-19 en América Latina y el Caribe, CEPAL. Recuperado de https://repositorio.cepal.org/bits tream/handle/11362/45782/4/S2000471_es.pdf 
Cóndor, V. (2017). Nuevas tendencias de la educación superior. La transformación de la Universidad Ecuatoriana. Revista Universidad y Sociedad, 9(3). http://scielo.sld.cu/scielo.php?script=sci_arttext\&p id=S2218-36202017000300022

Código Orgánico de Producción, Comercio e Inversiones (2018), 21 de agosto de 2018 (Ecuador).

Consejo de Educación Superior (12 de junio de 2019). Guía Metodológica para la Presentación de Carreras y Programas [Archivo PDF]. Recuperado de https://www.ces.gob.ec/documentos/RPC-SO-21-No_368 -2019.pdf

Consejo de Educación Superior (16 de diciembre de 2015). Reglamento para carreras y programas académicos en modalidad en línea a distancia y semipresenciales o de convergencia de medios [Archivo PDF]. Recuperado de https://www.ucsg.edu.ec/wp-content/uploads/pdf/distancia/reglamento_para _carreras.pdf

Constitución Política del Ecuador (2008), 20 de octubre de 2008 (Ecuador).

El Universo (20 de abril de 2020). Caída del precio del petróleo: las consecuencias para América Latina en medio de la crisis por el coronavirus. Recuperado de https://www.eluniverso.com/noticias/2020/04 /20/nota/7818714/precio-petroleo-coronavirus-consecuencias-ecuador-america-latina

García, J. (2013). Alianza del Pacífico. ¿Hacia dónde vamos? Agenda Internacional, 20(31), 43-54. https://re vistas.pucp.edu.pe/index.php/agendainternacional/article/view/7727

INEC (2020). Encuesta Nacional de Empleo, Desempleo y Subempleo. Indicadores laborales diciembre 2020. Recuperado de: https://www.ecuadorencifras.gob.ec/documentos/web-inec/EMPLEO/2020/Diciem bre-2020/202012_Mercado_Laboral.pdf

Ley Orgánica de Educación Superior del Ecuador (2018), 2 de agosto de 2018 (Ecuador).

Ministerio de Producción, Comercio Exterior, Inversiones y Pesca (18 de julio de 2020). Polos de desarrollo. Recuperado de http://www.polosdesarrollo.produccion.gob.ec/polos-de-desarrollo

Ministerio de Relaciones Exteriores y Movilidad Humana (2018). Agenda de Política Exterior 2017-2021. (Informe de gobierno) [Archivo PDF], 1-80.

Organización Internacional del Trabajo (2020). Perspectivas Sociales y del Empleo en el Mundo: Tendencias 2020. (Informe de Referencia de la OIT). Recuperado de https://www.ilo.org/wcmsp5/groups/public /---dgreports/---dcomm/---publ/documents/publication/wcms_734481.pdf

Pastrana E. y Gehring, H. (2014). La política exterior colombiana de cara al posconflicto. [Archivo PDF], 1-72. Recuperado de https://www.kas.de/c/document_library/get_file?uuid=62156d53-272f-7966-3 465-d085371a4942\&groupId=287914

Plan Nacional de Desarrollo (22 de septiembre de 2017) (Ecuador).

Schlemenson, A. (1998). Análisis organizacional y empresa unipersonal : Crisis y conflictos en contextos turbulentos. Editorial Paidos SAICF.

SENESCYT (2019). Oferta académica de las instituciones de educación superior [Archivo PDF], 1-104. Recuperado de http://admision.senescyt.gob.ec/media/2019/07/Oferta-2do-Semestre-2019_Digital .pdf

UNESCO (1998). Declaración Mundial sobre la educación superior en el siglo XXI: Visión y Acción. Educación Superior y Sociedad, 9(2), 97-113. https://www.iesalc.unesco.org/ess/index.php/ess3/article/view/ $\underline{171 / 162}$ 